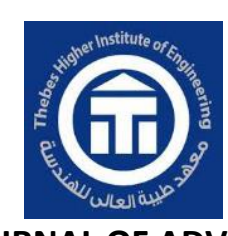

INTERNATIONAL JOURNAL OF ADVANCED ENGINEERING

AND BUSINESS SCIENCES (IJAEBS)

Journal homepage: International Journal of Advanced Engineering and Business Sciences (ekb.eg)

\title{
Drinking-Water Quality Monitoring Using WSN Technology
}

Amin S. Ibrahim

Electronics and Electrical Communications, Thebes Higher Institutes for Engineering, Cairo, Egypt

*Corresponding author: Email address: amin.alsaid@Thebes.edu.eg ，Tel: 01005819052

Received: 4 August 2021

Accepted: 20 August 2021

Published: 1 September 2021

\begin{abstract}
The Wireless Sensor Network (WSN) technology is the dense number of cooperative sensor nodes or terminals, which are densely deployed in the physical environment for sensing, wireless communications, and computational data statistics. The different academic and industrial applications have been developed based on wireless sensor networks. The drinking water quality monitoring system is proposed in this article as one of many applications, developed by WSN technology to diagnose the drinking water quality, thus solve their challenges as corruption, turbidity, and water neutrality. The paper presents the end-toend drinking water quality monitoring testbed including the Arduino controller, XBee communication unit, temperature sensor, LED and LDR sensors, and PH sensor. This module is experimentally calibrated, installed, and programmed using Arduino code as a lab model to prove the concept and measure the practical results.
\end{abstract}

Keywords: WSN; drinking water quality; XBee; PH sensor

\section{INTRODUCTION}

There is no doubt that water plays an important role in our life. So, people should be aware of the drinking water quality, healthy water, diseases caused by water pollutions, and how to monitor water quality. The drinking water tone?? measures are determined. According to World Health Organization (WHO) [1] guidelines for drinking-water tone as well as other pertinent systems, these systems set the standards for drinking water tone parameters and indicate which microbiological, chemical, and indicator parameters must be monitored and examined regularly to protect the health of the consumers and to make sure the water is healthy and clean [2].

A wireless sensor network (WSN) is a system consisting of a collection of nodes and a base station. A node is composed of a processor, local memory, sensors, radio, and battery. It is used to transmit the 
sensed data from the sensors to the base station. A base station (sink) is responsible for receiving and processing data collected by the nodes. They perform collaborative activities due to limited resources, such as battery, processor, and memory. Nowadays, the applications of WSN's are many and varied, and the applications in monitoring water quality are still incipient. One interesting WSN application is in drinking water, where the conditions such as $\mathrm{pH}$, temperature, and turbidity are to be monitored. In such an application, the sensors are fixed in the drinking water sample and WSN should guarantee real-time monitoring [3].

The paper is organized as follows: Section II presents the WSN system design methodology. The detailed hardware components are discussed in section III. Section IV describes the hardware implementation and the experimental results are displayed in section V. Finally, section VI shows the paper conclusion.

\section{SYSTEM MODEL}

\subsection{System overview}

Generally, a sensor network includes a large number of sensor nodes densely deployed in a region of interest, and one or more data sinks or base stations that are located close to or inside the sensing region, as shown in figure 1 . The $\operatorname{sink}(\mathrm{s})$ sends queries or commands to the sensor nodes in the sensing region while the sensor nodes collaborate to accomplish the sensing task and send the sensed data to the sink(s). Meanwhile, the sink(s) also serves as a gateway to outside networks.

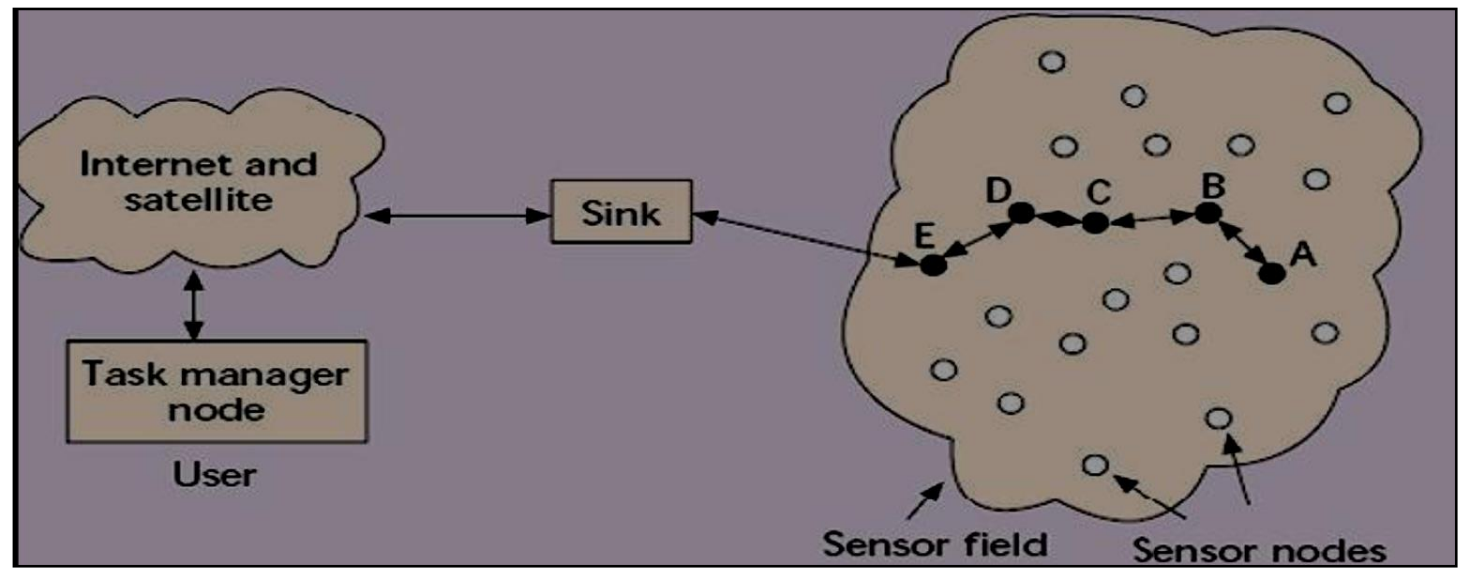

Fig.1 WSN architecture [4]

\subsection{System Design}

Similarly, in the drinking water quality monitoring module, the block diagram of the wireless sensor network consists of two main parts, the transmitting side and receiving side respectively. The transmitting side includes various sensor units (such as $\mathrm{pH}$, turbidity, and temperature), and makes the node module, which is made by ARDUINO and XBEE. At the receiving side, the transceiver XBEE module, the ARDUINO microcontroller, and USB cable are present along with the Personal Computer (PC). 
Arduino board will gather the data from sensors, convert that data into digital form, and send the data to the sink. The microcontrollers on the board are programmed using Arduino programming language based on wiring and Arduino development based on processing. Therefore, the Arduino module makes the XBEE module works as a transmitter/receiver on the transmitting side and allows the XBEE module to act as a receiver/transmitter on the receiving side. Both XBee units should be configured before making the interconnection of the two Tx and Rx sides. The drinking water quality parameters are observed on the PC through a USB cable that connects the Rx side and the PC. Figure 2 shows a simplified block diagram of the WSN system design.

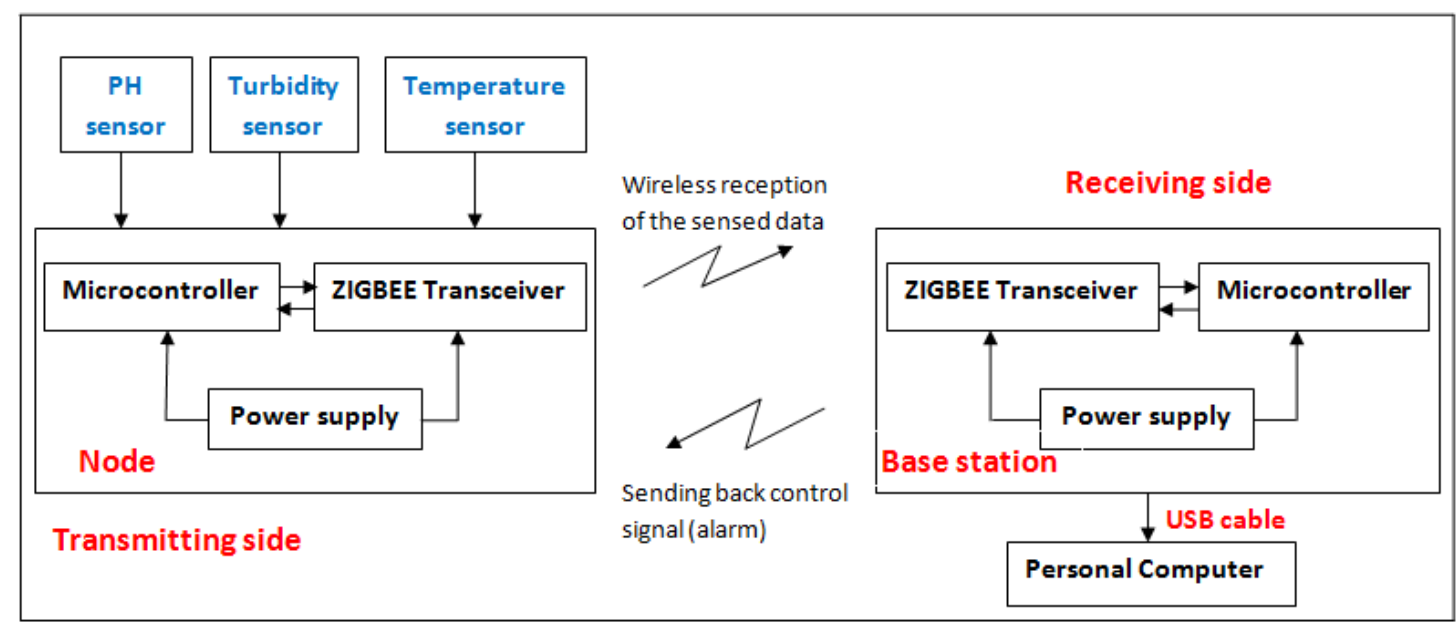

Fig.2 Simplified block diagram of WSN

\section{HARDWARE DESCRIPTION}

\subsection{Sensor units}

The sensor units are divided into three main types: Temperature sensor, Turbidity sensor, and $\mathrm{pH}$ sensor.

\subsubsection{Temperature sensor}

DS18B20 temperature sensor waterproof is used to sense the analog input temperature of the water. It also produces the digital output voltage (data). Figure 3 shows a typical DS18B20 temperature sensor and its output leads. This is a pre-wired and waterproof version of the DS18B20 sensor allweather/submersible temperature probe, specifically designed to be used in the field. It is a digital sensor so no signal degradation even over long distances. Information is sent to/from the DS18B20 over a 1-Wire interface so that only one wire (and ground) needs to be connected from a central microprocessor to a DS18B20 [5]. This sensor can be used in several applications including thermostatic controls, industrial systems, consumer products, thermometers, or any thermally sensitive system. Table I lists the DS18B20

Amin S, IJAEBS (2021), (Vol. 2), (Issue2), (p.1-14) 
digital temperature sensor. Finally, measuring the temperature parameters provides the $\mathrm{pH}$ of the drinking water quality.

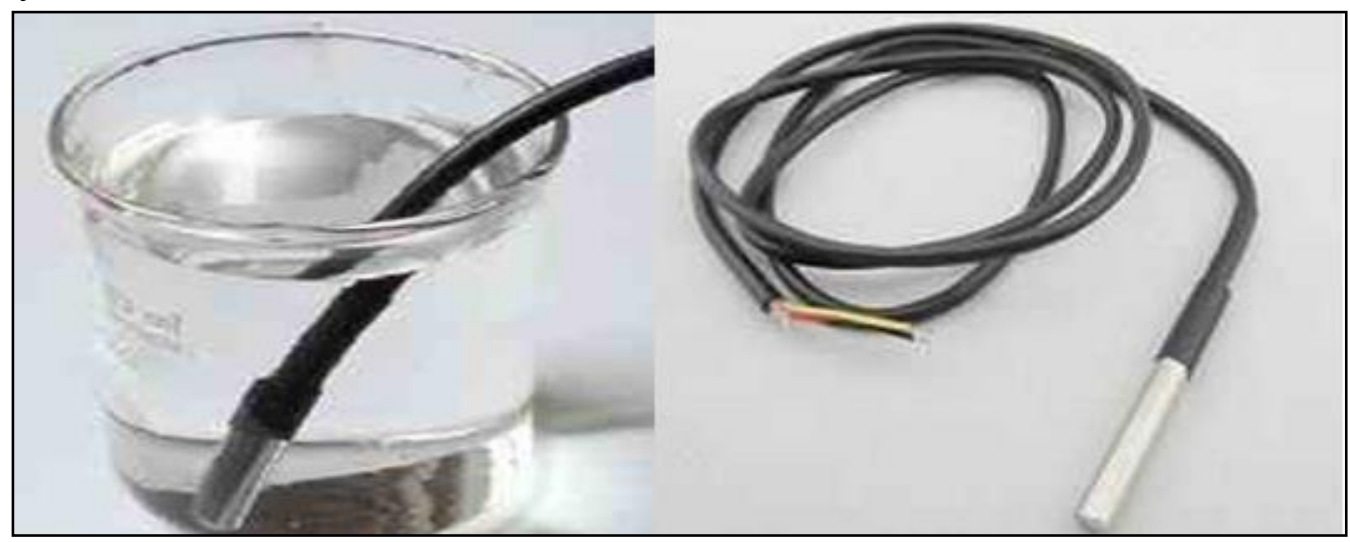

Fig.3 Typical DS18B20 temperature sensor (waterproof)

Table I. DS18B20 temperature sensor specifications

\begin{tabular}{|l|l|}
\hline \multicolumn{1}{|c|}{ Item } & Value \\
\hline Temperature range & $-55^{\circ} \mathrm{C}$ to $+125^{\circ} \mathrm{C}\left(-67^{\circ} \mathrm{F}\right.$ to $\left.+257^{\circ} \mathrm{F}\right)$ \\
\hline Temperature resolution & $0.5^{\circ} \mathrm{C}, 0.25^{\circ} \mathrm{C}, 0.125^{\circ} \mathrm{C}$, or $0.0625^{\circ} \mathrm{C}$ \\
\hline Resolution bits & $9,10,11$, or 12 bits \\
\hline Accuracy & $0.5 \square \mathrm{C}$ accuracy from $-10^{\circ} \mathrm{C}$ to $+85^{\circ} \mathrm{C}$ \\
\hline Query time & $750 \mathrm{~ms}$ (max.) for 12 -bit resolution \\
\hline Power supply & $3.0 \mathrm{~V}$ to $5.5 \mathrm{~V}$ \\
\hline Output leads & red (Vcc), blue or yellow(Data), black (GND) \\
\hline
\end{tabular}

\subsubsection{Turbidity sensor}

The turbidity sensor measures the cloudiness or haziness of a fluid caused by large numbers of individual particles which are invisible to the naked eye. The measurement of turbidity is a key test of drinking water quality. Turbidity can be measured electronically using optoelectronic devices, which is a combination of a visible light source such as Red Light Emitting Diode (LED) or laser and light detector i.e. Light Dependent Resistance (LDR). LDR changes its resistance according to light intensity. Normally the LDR resistance decreases with increasing the intensity of light falling on it [6]. Figure 4 shows the turbidity measurement using the visible LED source and the LDR detector. The visible light is transmitted from the LED, when this light hits the particles the light will reflect and will be received by the photoresistor. 


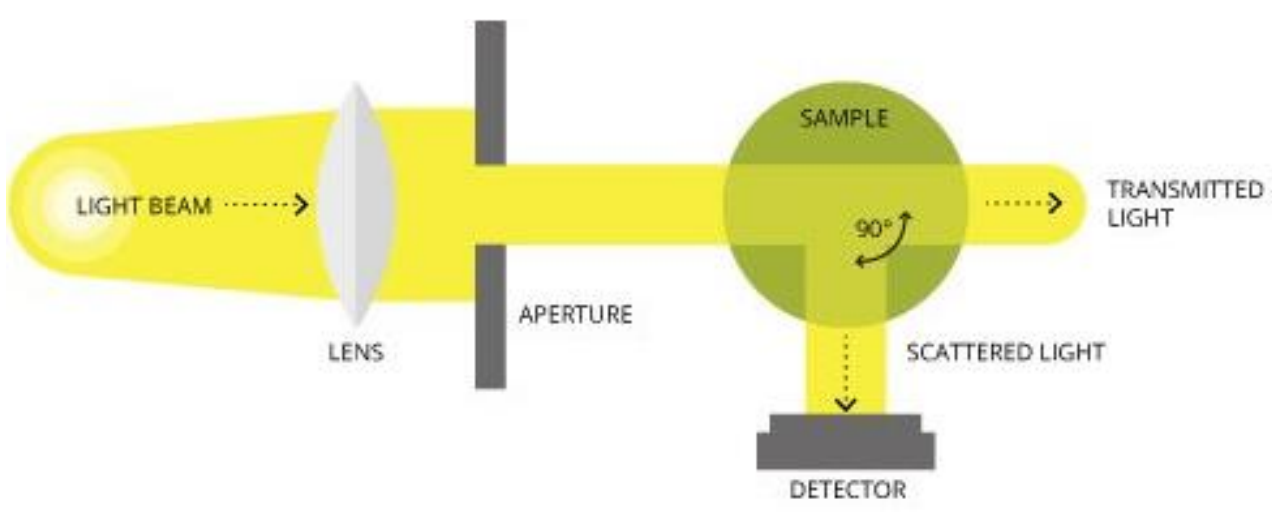

Fig.4 Turbidity measurements

\section{a) Turbidity measurements:}

Turbidity measurements are classified into the following two methods: The nephelometer method and the Turbidimeter method.

\section{- The nephelometer method:}

Measures directly the intensity of light scattered by the sample. The light intensity is directly proportional to the amount of matter suspended in the light path. The sensor is mounted at an angle (usually 90 degrees) to the traversing beam to record scattered light. Nephelometers usually provide greater precision and sensitivity than turbidimeters and are normally used for samples of low turbidity containing small particles.

- The turbidimeter method, sometimes called the absorption meter, measures the intensity of the beam after it has passed through the sample. Suspended matter in the light path causes scattering and absorption of some light energy. The transmitted light is measured, related to initial beam intensity. Turbidimeters are more appropriate for relatively turbid samples in which the scattering particles are large with the light wavelength used.

- NTU Turbidity measurement: The turbidity sensor detector converts the scattered light into the output voltage. The output sensor voltage can also be converted into a Nephelometric Turbidity Unit (NTU) of turbidity. Based on the commercial nephelometer turbidity standard [3], the turbidity $T$ (in $N T U$ ) to the $L D R$ voltage readings $V o$ (in $V$ ) relation of the proposed turbidity sensor as shown by the following equation [7]:

$$
T=132.69 * V o-1.418
$$

Also, the turbidity of each sample is measured both by the turbidity sensor under calibration and by a laboratory turbid meter (Lutron TU-2016) used as a reference. Turbidity (in NTU) and the voltage output (in $\mathrm{mV}$ ) of the turbidity sensor are extracted and given by:

Amin S, IJAEBS (2021), (Vol. 2), (Issue2), (p.1-14) 


$$
T U=0.1035 \mathrm{~V}-0.292
$$

\subsection{3 pH sensor}

$\mathrm{PH}$ sensor is used to determine whether the water solution is base or acid. Exactly, $\mathrm{pH}$ is the measurement of the hydrogen ion concentration, $[\mathrm{H}+]$ in acid solutions and $\mathrm{OH}$ or $[\mathrm{H}-]$ in base solutions. Every water solution can be measured to determine its $\mathrm{pH}$ value. The total $\mathrm{pH}$ range is $0-14$, strong acid to a strong base. As seen in figure 5, the $\mathrm{pH}$ sensor generates zero voltage output at neutral $\mathrm{pH}=7$, the positive voltage at acids $\mathrm{pH}<7$, and negative voltage at basic $\mathrm{pH}>7$. The $\mathrm{pH}$ sensor is made with glass which contains a Probe. The probe is the main part of this sensor. The glass type combination $\mathrm{pH}$ electrode is used to sense the $\mathrm{pH}$ and is shown in Figure 6.

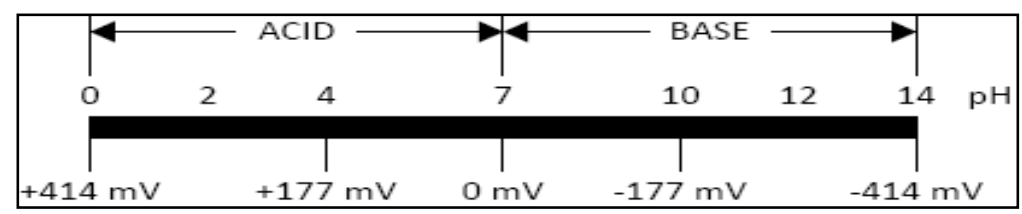

Fig.5 pH scale [8]

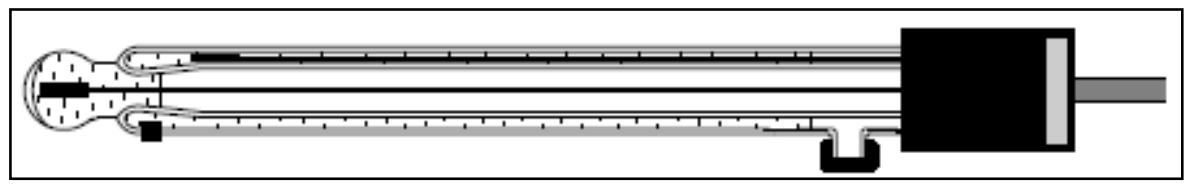

Fig.6 Typical pH sensor electrode [3]

\section{b) pH Electrode Characteristics:}

The $\mathrm{pH}$ electrode is a passive sensor, which means no excitation source (voltage or current) is required. Because the electrode's output can swing above and below the reference point, it is classified as a bipolar sensor. It produces a voltage output that is linearly dependent upon the $\mathrm{pH}$ of the solution being measured. The source impedance of a $\mathrm{pH}$ electrode is very high because the thin glass bulb has a large resistance that is typically in the range of $10 \mathrm{M} \Omega$ to $1000 \mathrm{M} \Omega$. This means that the electrode can only be monitored by a high-impedance measuring device.

Figure 7 illustrates the transfer function of $\mathrm{pH}$ that reflects the output voltage reading values of $\mathrm{pH}$ electrode to $\mathrm{pH}$ value relation as a function of temperature degree. For example, at $25^{\circ} \mathrm{C}$, electrode sensitivity is $59.16 \mathrm{mV} / \mathrm{pH}$ and the output of the electrode will swing from $-7 \mathrm{pH} \times-59.16 \mathrm{mV} / \mathrm{pH}=$ $+414.12 \mathrm{mV}$ (pH 0 strong acid) to $+7 \mathrm{pH}$ x $-59.16 \mathrm{mV} / \mathrm{pH}=-414.12 \mathrm{mV}$ (pH 14 strong base). However, if the measured solution temperature is increased to $100^{\circ} \mathrm{C}$, the output will swing from $-7 \mathrm{pH} \mathrm{x}-74.04$ $\mathrm{mV} / \mathrm{pH}=+518.29 \mathrm{mV}$ down to $+7 \mathrm{pH} \times-74.04 \mathrm{mV} / \mathrm{pH}=-518.29 \mathrm{mV}$ as shown in figure 5 . 
The transfer function of the $\mathrm{pH}$ electrode is depicted in equation [8]:

$$
P H(X)=P H(S)+\frac{\left(E_{S}-E_{X}\right)}{R T \ln (10)} F
$$

It is important to note that a $\mathrm{pH}$ electrode's sensitivity varies over temperature. Looking at the $\mathrm{pH}$ electrode transfer function shows that the sensitivity linearly increases with temperature according to equation below:

$$
\begin{aligned}
& \frac{R T \ln (10)}{F}=0.000198 T \quad V / P H \\
& P H(X)=P H(S)+\frac{\left(E_{S}-E_{X}\right)}{0.000198 T} F
\end{aligned}
$$

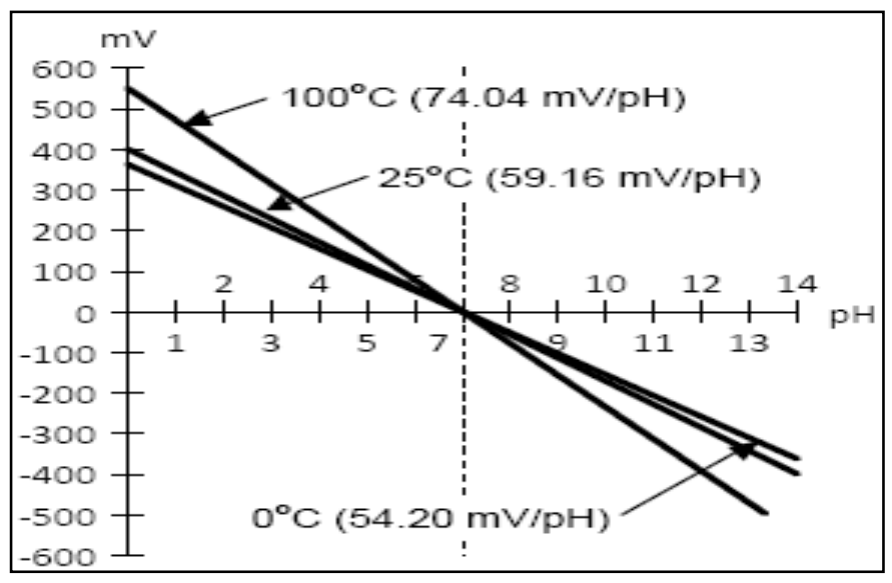

Fig.7 pH electrode transfer function [8]

\section{c) GL-24 pH-Electrode Circuit interface:}

Because the $\mathrm{pH}$ electrode produces a bipolar signal and passive sensor, the signal will have to be levelshifted. Second, due to the high impedance of the electrode, a high-input impedance buffer will be required. Finally, the temperature of the measured solution must be known to compensate for the electrode's sensitivity variation over temperature [8].

The $\mathrm{pH}$ electrode consists of a $\mathrm{pH}$ probe and $\mathrm{BNC}$ connector that includes data pin and ground. This $\mathrm{pH}$ electrode and DS18B20 digital temperature sensor are connected to the $\mathrm{pH}$ electrode circuit interface as shown in figure 8 which solves all three design challenges. The $\mathrm{pH}$ electrode consists of three op amplifier Circuits; Buffer op-amp, offset op-amp, and amplifier op-amp. The first U1A amplifier buffers the output of the $\mathrm{pH}$ electrode due to the high impedance of the $\mathrm{pH}$ probe. The output of the buffer amplifier is set up in a unity-gain configuration bias the reference electrode of the $\mathrm{pH}$ electrode with the same voltage. The second op-amp offsets the $\mathrm{pH}$ electrode by $500 \mathrm{mV}$ to avoid the negative voltage output in the $\mathrm{pH}$ probe. The offset amplifier is achieved by using the voltage divider between $100 \mathrm{k} \Omega$ 
potentiometer and fixed $0.91 \mathrm{M} \Omega$ resistor. The voltage across the $100 \mathrm{k} \Omega$ potentiometer divider is equal to about $500 \mathrm{mV}$. The second amplifier U2A is set up in a unity-gain configuration. The last one U3A amplifier is used as an amplifier with a gain equal to 5. Practically, the gain will be about 4.7 because of the resistance values. All op-amps use a double supply. Now the $\mathrm{pH}$ electrode readings can be transmitted into ARDUINO for programming.

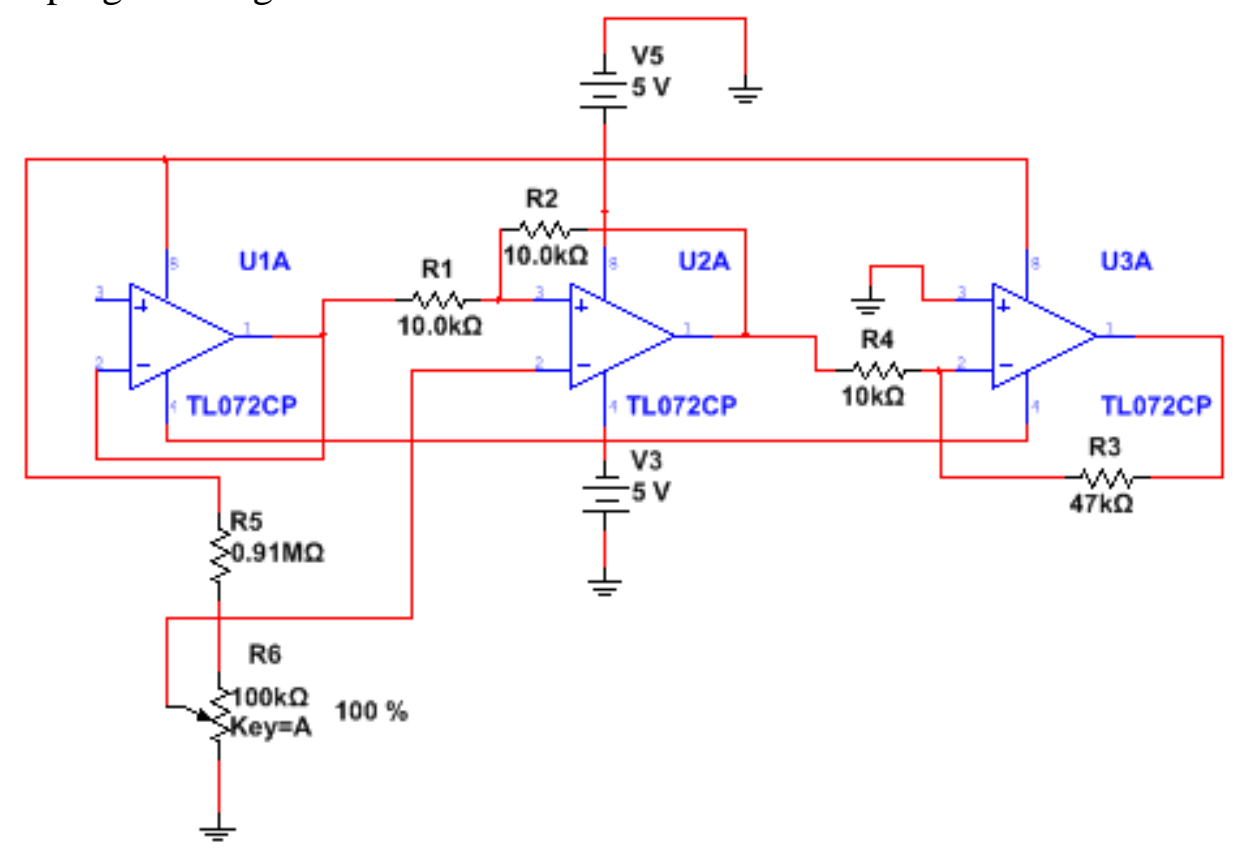

Fig.8 pH-electrode Circuit interface

\section{- ARDUINO module}

ARDUINO UNO controls and manages all external components for both transmitting and receiving entities in WSN system architecture. ARDUINO module is a microcontroller board based on the ATmega328. It has 14 digital input/output pins (of which 6 can be used as PWM outputs), 6 analog inputs, a $16 \mathrm{MHz}$ crystal oscillator. The Uno is the latest in a series of USB ARDUINO boards and the reference model for the ARDUINO platform for a comparison with previous versions. The diagram of the ARDUINO microcontroller would be shown in figure 9. The ARDUINO Uno can be powered via a USB connection or with an external power supply with a recommended range from 7 to 12 volts [9]. 


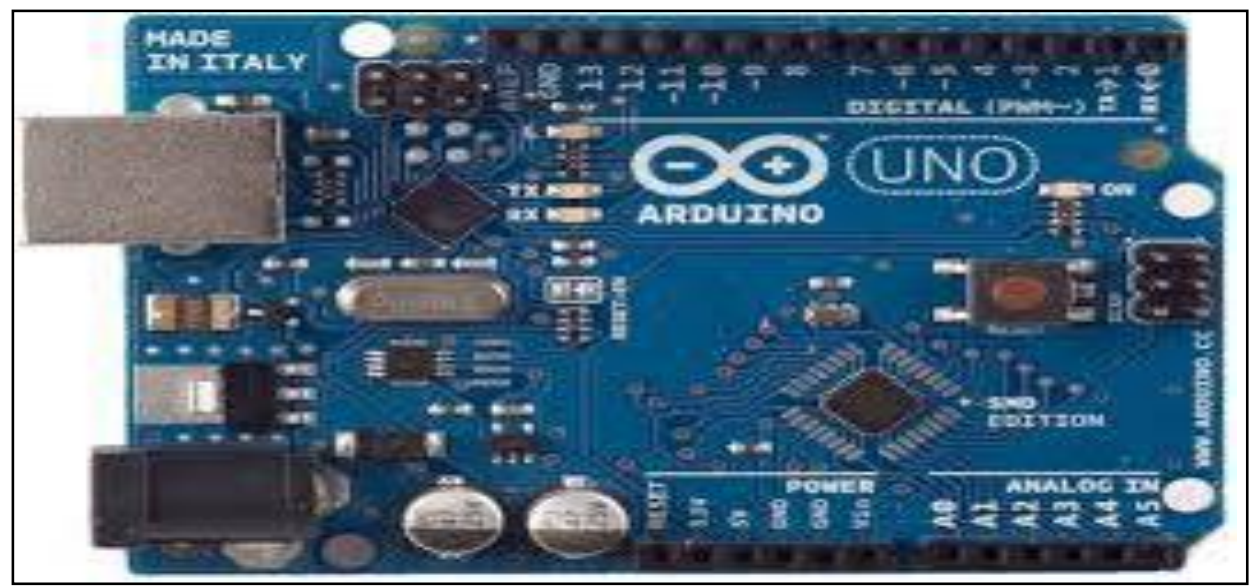

Fig.9 Typical ARDUINO UNO microcontroller [9]

\section{- XBEE module}

The main function of the XBee module is to communicate between both ends of our WSN system architecture. Zigbee technique provides XBee module. ZigBee is a specification for a suite of high-level communication protocols used to create personal area networks built from small, low-power digital radios. It is based on an IEEE 802.15.4 protocol and its low power consumption limits transmission distances to 10-100 meters. This technique is targeted at applications that require a low data rate, long battery life, and secure networking. It has a defined rate of $250 \mathrm{kbit} / \mathrm{s}$ and is best suited for periodic or a single signal transmission from a sensor. A typical XBee module and its diagram are depicted in figure 10. According to the network application, the XBee module may be the end device, Router, coordinator, or gateway.

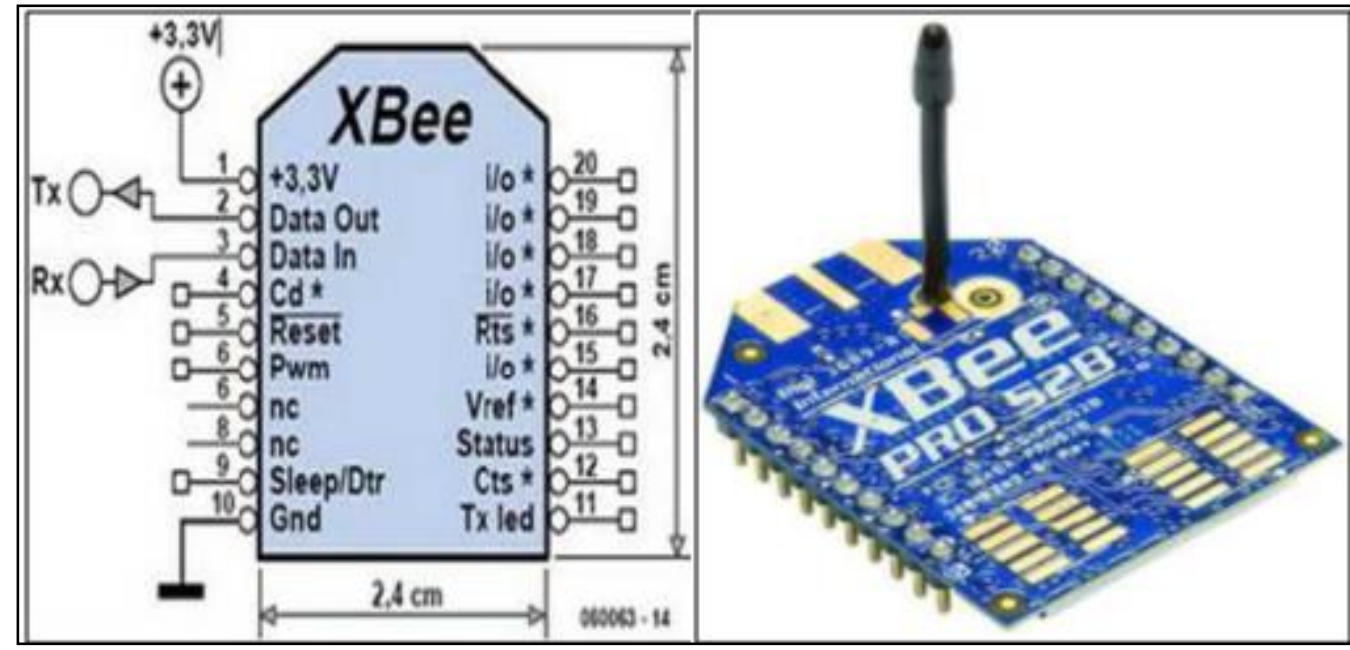

Fig.10 Typical XBee module and its pin diagram 


\section{HARDWARE IMPLEMENTATION}

\subsection{Connection and Interfacing}

In this paper, all hardware components are integrated to monitor and measure $\mathrm{pH}$, turbidity, and temperature of water solution. DS18B20 digital temperature sensor detects the temperature of the water solution and converts it into digital data, which are launched into ARDUINO UNO. A passive bipolar $\mathrm{pH}$ electrode is biased by both the preamplifier circuit and the offset circuit. ARDUINO UNO uses both the output $\mathrm{pH}$ readings $(\mathrm{mV} / \mathrm{pH}$ value) and the digital temperature values for measuring $\mathrm{pH}$ values from the above $\mathrm{pH}$ transfer function.

In the turbidity sensor, the red LED transmits the light pulses periodically into the water after biased from the ARDUINO kit. The LDR photoresistor detects the scattered light from the solid particles in a water sample and converts it into the corresponding analog voltage. ARDUINO can determine the NTU from any of the two turbidity equations as illustrated in section 3.2.1. Figure 11 shows a simplified block diagram of hardware implementation at the sensor field.

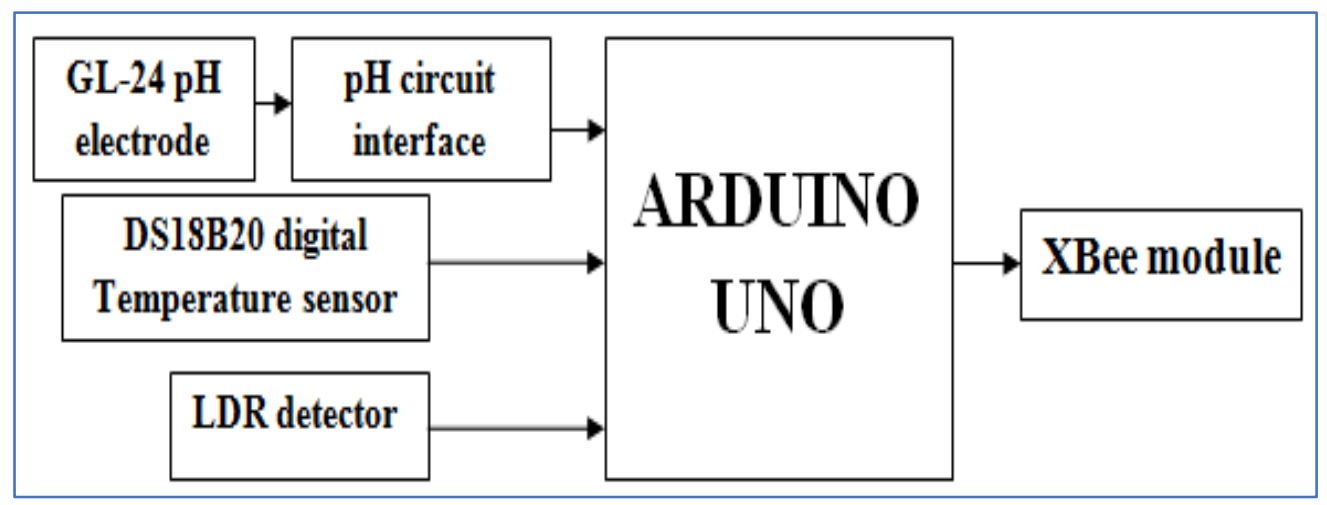

Fig.11 a simplified diagram of the hardware structure of sensor node

The connection between the XBee module and ARDUINO board is important for the communication process to make the interconnection between both end sides of the system design. Before the communication process, both XBee modules should be configured via the X-CTU program. This configuration occurs in AT mode that makes a point-to-point connection between two distinct entities. In our paper, one XBee module is configured as a router. While another one is configured as a coordinator.

All sensed data can be transferred from the node side of the sensor field into the sink side using XBee modules. The base station forwards these data into the PC through USB serial cable. 


\subsection{ARDUINO code}

Figures 12.a and 12.b explain the ARDUINO code format of the turbidity sensor and temperature with $\mathrm{pH}$ sensors, respectively. At sensor field, the ARDUINO code defines/declares the $\mathrm{pH}$ electrode and LDR in turbidity as analog input sensors, one wire DS18B20 temperature as a digital input. While red LED of turbidity is connected as an output of ARDUINO.

The analog readings of the turbidity sensor are extracted from the ARDUINO code using analogRead( ) function. The temperature value is also detected using gettemp( ) function. This code also involves all specified mathematical equations, which are specified to $\mathrm{pH}$ and NTU values.

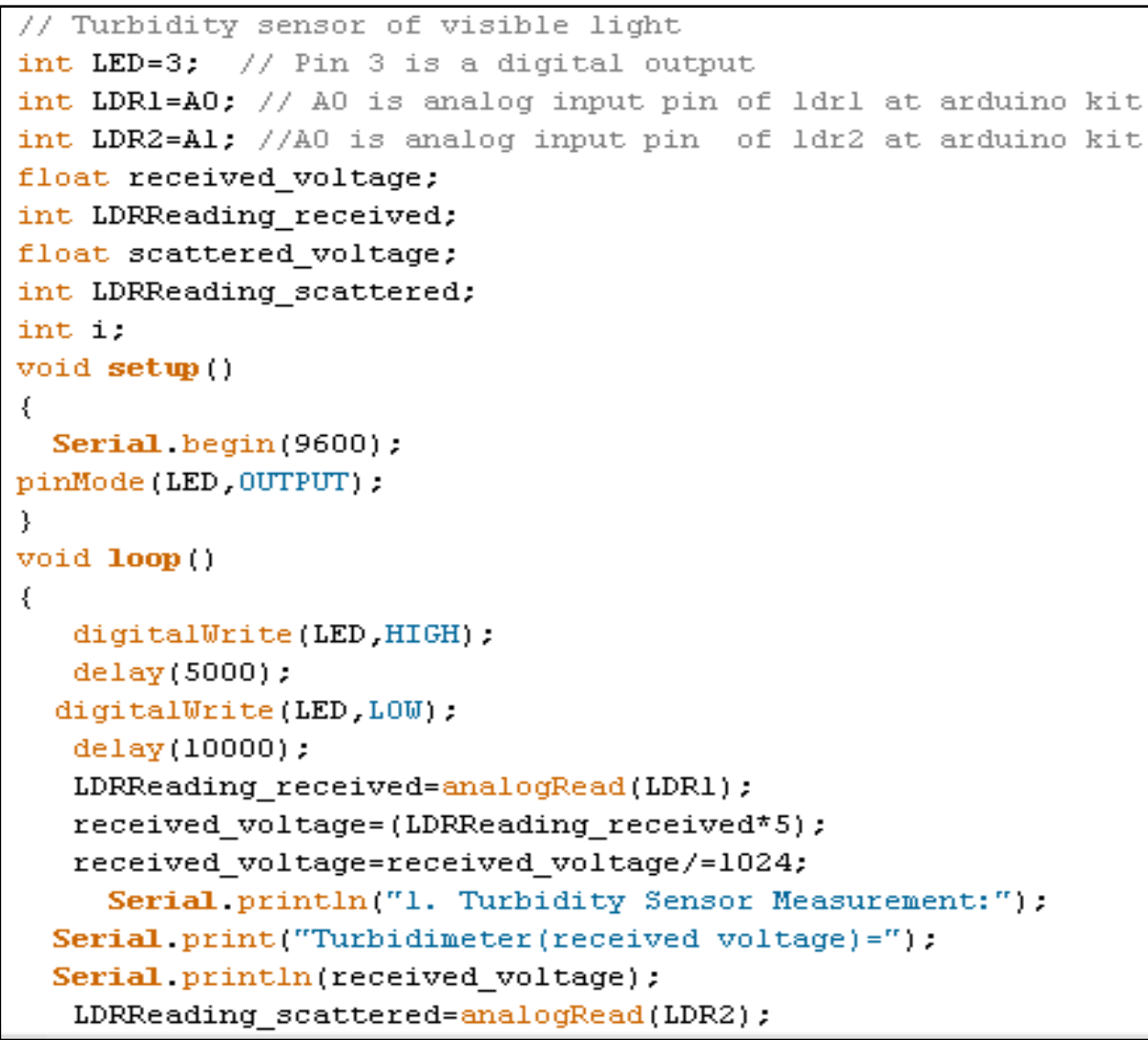

Fig. 12.a Turbidity Sensor ARDUINO Code 


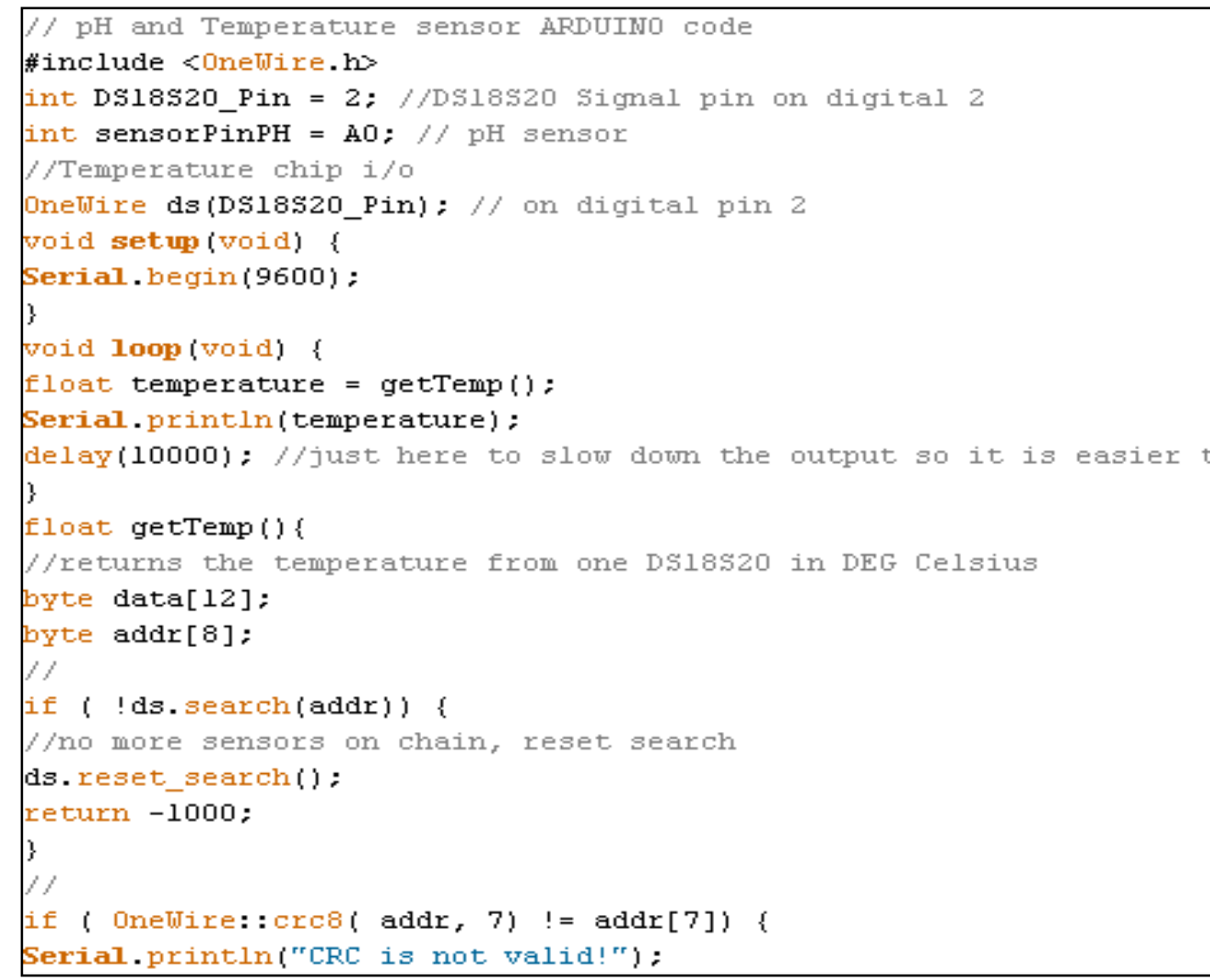

Fig.12.b pH and temperature ARDUINO code

At the sink (Rx side), a serial receiver code and XBee develop the receiving sensed data from the tx side. Finally, the ARDUINO code views the sensed data via a serial monitor page of ARDUINO. Figure 13 explains the serial communication code at the receiver.

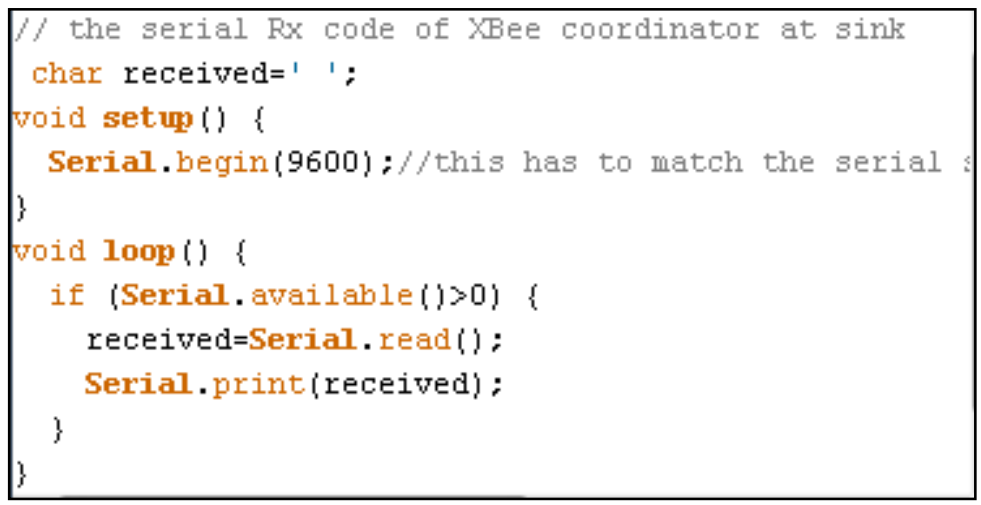

Fig. 13 serial $R x$ code at a base station 


\section{EXPERIMENTAL RESULTS}

All sensed data results are displayed through a serial monitor window. On the sink side, a serial receiver code was used to receive all sensed parameters at the PC of the WSN system design. The NTU turbidity measurement is subject to the calibration and the turbidimeter or nephelometer lab. So, the results of the turbidity sensor in this experiment are measured per voltage as listed in table II.

Table II. Turbidity results for both turbidimeter and nephelometer

\begin{tabular}{|l|l|l|}
\hline Water solution & Turbidimeter method & Nephelometer method \\
\hline Filtered water & $1.38 \mathrm{~V}$ & $0.12 \mathrm{~V}$ \\
\hline Low turbidity & $1.36 \mathrm{~V}$ & $0.17 \mathrm{~V}$ \\
\hline Medium turbidity & $1.42 \mathrm{~V}$ & $0.19 \mathrm{~V}$ \\
\hline High turbidity & $1.47 \mathrm{~V}$ & $0.20 \mathrm{~V}$ \\
\hline
\end{tabular}

In our experiment, the GL-42 $\mathrm{pH}$ electrode output measures the acids and base solutions in terms of $\mathrm{mV}$ from $+400 \mathrm{mV}$ to $-400 \mathrm{mV}$ range. For acids solutions, it measures a difference potential voltage between unknown $[\mathrm{H}+]$ solutions to a reference potential of internal $[\mathrm{H}+]$. While the $\mathrm{pH}$ probe measures the concentration of $[\mathrm{OH}]$ or $[\mathrm{H}-]$ base solutions. Table III readouts some acids and base solution readings from GL-42 $\mathrm{pH}$ electrode.

Table III. GL-42 pH probe output readings

\begin{tabular}{|c|l|l|l|l|l|l|l|}
\hline Solution & Water & $\mathrm{H}_{2} \mathrm{SO}_{4}$ & $\mathrm{BaCL}_{2}$ & Ammonia & Sabon & $\begin{array}{l}\text { Lemon } \\
\text { juice }\end{array}$ & Pepsi \\
\hline $\begin{array}{c}\text { pH probe } \\
\text { readings(mV) }\end{array}$ & $-8 \sim-20$ & +400 & +287 & -306 & $-30 \sim-42$ & $\begin{array}{l}+81 \sim \\
+102\end{array}$ & $243 \sim 245$ \\
\hline Type & Neutral & Acid & Acid & Base & Base & Acid & Acid \\
\hline
\end{tabular}

\section{CONCLUSION}

The drinking water parameters i.e., temperature, turbidity, and $\mathrm{pH}$ are monitored and examined regularly to protect the health of the consumers and to make sure the water is healthy and clean. $\mathrm{pH}$ parameter value was detected using the instantaneous temperature value and the corresponding output voltage $(\mathrm{mV} / \mathrm{pH})$ value that was produced from the passive $\mathrm{pH}$ sensor. For turbidity sensors, a simple red LED and LDR components can detect if the drinking water sample has low turbidity or high turbidity according to the scattered light detector. The lower the turbidity the greater the amount of transmitted light and vice versa and the lower the turbidity the lower the amount of scattered light and vice versa. Temperature, turbidity, and $\mathrm{pH}$ parameters are controlled via ARDUINO and transferred into the other entity using wireless XBee. Finally, both transmitting and receiving serial communication codes on ARDUINO integrate and provide transferring the sensed data from the sensor field to the base station in our WSN system design.

Amin S, IJAEBS (2021), (Vol. 2), (Issue2), (p.1-14) 


\section{REFERENCES}

[1] Guidelines for Drinking-Water Quality, World Health Organization, Geneva, Switzerland, 2011

[2] J.Ramprabu and C.Paramesh, "Embedded Based Real-Time Monitoring and Contamination Detection in Drinking Water Distribution System", International Journal of Emerging Trends and Technology for Computer Sciences (IJETTCS), 2014

[3]Santoshkumar, Vishal Hiremath." Design and Development of Wireless Sensor Network System to Monitor Parameters Influencing Freshwater Fishes", International Journal on Computer Science and Engineering, Vol. 4 No. 06 June 2012

[4] Samira Kalantary*, Sara Taghipour.," A survey on architectures, protocols, applications, and management in wireless sensor networks", Journal of Advanced Computer Science \& Technology, 2014.

[5] DS18B20 digital temperature sensor waterproof datasheet

[6] A.C.Khetre, Prof.S.G.Hate, " Automatic monitoring \& Papering of water quality by using WSN Technology and different routing methods", International Journal of Advanced Research in Computer Engineering \& Technology (IJARCET) Volume 2, Issue 12, December 2013

[7] Theofanis P. Lambrou, Christos C. Anastasiou, Christos G. Panayiotou, "A Nephelometric Turbidity System for Monitoring Residential Drinking Water Quality, Sensor Applications", Springer, 2010

[8] AN-1852 designing with $\mathrm{pH}$ Electrodes, Texas instruments, Application Paper SNOA529A-September 2008-Revised April 2013

[9] Hemanth Kumar CH, Sowmya I, "Low-Cost Sensor Network for Contamination Detection in Drinking Water", Hemanth Kumar CH Int. Journal of Engineering Research and Applications, Vol. 5, Issue 4, (Part -4) April 2015, pp.71-74 